\title{
QUEEN'S
UNIVERSITY
BELFAST
}

\section{To breathe or fight? Siamese fighting fish differ when facing a real opponent or mirror image}

Arnott, G., Beattie, E., \& Elwood, R. W. (2016). To breathe or fight? Siamese fighting fish differ when facing a real opponent or mirror image. Behavioural Processes, 129, 11-17. https://doi.org/10.1016/j.beproc.2016.05.005

\section{Published in:}

Behavioural Processes

\section{Document Version:}

Peer reviewed version

Queen's University Belfast - Research Portal:

Link to publication record in Queen's University Belfast Research Portal

\section{Publisher rights}

(C) 2016 Elsevier B. V. All rights reserved. This manuscript version is made available under the CC-BY-NC-ND 4.0 license

http://creativecommons.org/licenses/by-nc-nd/4.0/ which permits distribution and reproduction for non-commercial purposes, provided the author and source are cited.

\section{General rights}

Copyright for the publications made accessible via the Queen's University Belfast Research Portal is retained by the author(s) and / or other copyright owners and it is a condition of accessing these publications that users recognise and abide by the legal requirements associated with these rights.

Take down policy

The Research Portal is Queen's institutional repository that provides access to Queen's research output. Every effort has been made to ensure that content in the Research Portal does not infringe any person's rights, or applicable UK laws. If you discover content in the Research Portal that you believe breaches copyright or violates any law, please contact openaccess@qub.ac.uk. 
2 image.

3

4

5 Gareth Arnott*, Emma Beattie, Robert W. Elwood

6

7

8 Institute for Global Food Security, School of Biological Sciences, Queen's University Belfast, 9 U.K.

10

11

12 Accepted by Behavioural Processes, 23 ${ }^{\text {rd }}$ May 2016

13

14

15

16

17

18

19

20

21

22

23

24 
26 Displays are a feature of animal contest behaviour and have been interpreted as a means of gathering information on opponent fighting ability, as well as signalling aggressive motivation. In fish, contest displays often include frontal and lateral elements, which in the latter involves contestants showing their flanks to an opponent. Previous work in a range of fish species has demonstrated population-level lateralization of these displays, preferentially showing one side to their opponent. Mirrors are commonly used in place of a real opponent to study aggression in fish, yet they may disrupt the normal pattern of display behaviour. Here, using Siamese fighting fish, Betta splendens, we compare the aggressive behaviour of males to a mirror image and real opponent behind a transparent barrier. As this species is a facultative air-breather, we also quantify surface breathing, providing insights into underlying fight motivation. Consistent with previous work, we found evidence of population-level lateralization, with a bias to present the left side and use the left eye when facing a real opponent. Contrary to expectations, there were no differences in the aggressive displays to a mirror and real opponent, with positive correlations between the behaviour in the two scenarios. However, there were important differences in surface breathing, which was more frequent and of longer duration in the mirror treatment. The reasons for these differences are discussed in relation to the repertoire of contest behaviour and motivation when facing a real opponent.

Keywords: aggression, contests, lateralization, mirrors, surface breathing. 


\section{Introduction}

50 Although there is considerable taxonomic variation in contest behaviour (Arnott and Elwood 2009a; Hardy and Briffa 2013), displays typically precede and intersperse with escalated fighting behaviour. These displays are usually interpreted as providing a means of gathering information on the size and fighting ability, termed resource holding potential (RHP), of an opponent (Parker 1974). However, evidence to support this interpretation is often lacking (Taylor and Elwood 2003; Arnott and Elwood 2009a; Elwood and Arnott 2012, 2013; Fawcett and Mowles 2013). An alternative view is that they serve to signal information about the aggressive motivation of each contestant (Camerlink et al. 2015).

The prefight display phases are typically dynamic processes involving the contestants interacting in a particular pattern. There are numerous examples across diverse taxa, and for invertebrates these include; the prefight cheliped displays of hermit crabs (Elwood et al. 2006), the waving of the enlarged claw during fiddler crab contests (Backwell et al. 2000) and of legs in spiders (Elwood and Prenter 2013). Commonly cited vertebrate examples include; the stereotyped displays of lizards (Van Dyk and Evans 2008) and frogs (Reichert and Gerhardt 2014), the mutual vocal displays occurring between male red deer (Clutton-Brock and Albon 1979) and fallow deer (Jennings et al. 2012), as well as the conspicuous lateral visual displays termed parallel walks occurring in these ungulates (Jennings and Gammell 2013). themselves to laboratory and field studies (e.g. Enquist et al. 1990). The contest displays of many fish comprise frontal displays and lateral displays, which in the latter involves contestants showing their flanks to an opponent. During lateral displays, fish can align in two ways, with their heads either facing in the same direction (head to head) or in opposite 
directions (head to tail). Moreover, a range of fish species has been shown to exhibit population-level lateralization, preferentially showing one side to their opponent (Bisazza and de Santi 2003; Reddon and Balshine 2010). For example, competing convict cichlids, Amatitlania nigrofasciata, more commonly show their right than their left flank (Arnott et al. 2011; Elwood et al. 2014). When both contestants show their right side the head to tail configuration results and this is more common than the head to head configuration (Arnott et al. 2011). Such population-level lateralization of displays thus provides some predictability and enables coordination of these agonistic interactions (Ghirlanda et al. 2009), potentially facilitating a mutual assessment process (Arnott et al. 2011). Additionally, it may also act to reduce the likelihood of injury should one fish escalate the contest (Rogers 1989; Bisazza et al. 2000; Arnott et al. 2011). The importance of coordinating displays in fish, such as head to tail positioning, can be examined by comparing mirror images to live opponents behind a transparent partition (Elwood et al. 2014), because with a mirror the fish can never align in the head to tail configuration and this key feature of the mutual display is lost.

Nevertheless, mirrors are frequently used instead of a live opponent in studies on aggression in fish (Cantalupo et al. 1996; Earley et al. 2000; Wilson et al. 2011; Balzarini et al. 2014). Mirror images might be a good choice of stimuli when repeated measures design require several bouts and opponent variability can be avoided. However, the validity of using mirrors for studying contest behaviour has been questioned. For example, mirror images fail to elicit the same brain gene expression (Desjardins and Fernald 2010) or the same hormonal responses (Oliveira et al. 2005) as live opponents. Furthermore, Elwood et al. (2014) recently compared the displays of convict cichlids to a mirror and a real opponent, finding a lower frequency of displays to a mirror but with individual displays of greater duration. This slower pace of the interaction to a mirror suggested that social responses from opponents are a key 
component necessary to elicit the normal repertoire of contest behaviour, as has also been suggested for lizards (Ord and Evans 2002). The presence of an appropriately responding opponent during aggressive displays thus appears to be a key driver necessary for the interaction to progress.

Although only focussing on displays in their study, Elwood et al. (2014) predicted that the disruption of normal display behaviour caused by the mirror may lead fish to abandon displays in favour of other activities, including other forms of aggression such as biting. This is one focus of the current study. In addition, Elwood et al. (2014) confirmed previous findings of population-level lateralization in the convict cichlid (Arnott et al. 2011), with a right-sided lateral display bias that was evident to both a real opponent and when facing a mirror. With Siamese fighting fish, Betta splendens, interacting with real opponents and when facing a mirror image there was evidence of population-level right side bias (Bisazza and de Santi 2003), but this was not found in other studies with a mirror (Cantalupo et al. 1996; Takeuchi et al. 2010). A recent study demonstrated a population-level right side preference to real opponents during early reproductive stages but not at late stages (Forsatkar et al. 2015). Indeed, some individuals switched from a right side bias to a left side bias after spawning thus illustrating the confusion about laterality in this species. Here we use B. splendens in mirror and real opponent tests to examine population-level lateralization. Further, we test the predictions of Elwood et al. (2014) concerning the utility of a mirror image in eliciting normal contest behaviour and, in particular, if the motivation to compete is the same to a mirror as to a real opponent. B. splendens offers a widely used model for studies on aggression (e.g. Simpson 1968). Their pre-fight displays consist of raised opercula and spread fins during frontal displays and lateral displays (Castro et al. 2006). The frontal displays impair respiration and are physiologically demanding such that contestants will interrupt the display 
sequence at intervals to engage in surface breathing (Regan et al. 2015).

We recorded the frequency, total duration and the median duration of left lateral displays, right lateral displays, frontal displays, and surface breathing, as well as attempted bite frequency. The frequency and median duration should relate positively and negatively to vigour whereas total duration is the product of frequency and median duration and is the more commonly used measure of displays. Using this information we examine four key predictions. First, consistent with the findings of Elwood et al. (2014), we predict there will be evidence of population-level lateralization when displaying to both a mirror and real opponent. Second, we predict the mirror will elicit a decreased frequency of displays and longer duration of individual displays than when facing a real opponent. Third, we predict if the mirror impairs the normal sequence of displays, individuals may switch to more escalated aggression revealed by increased levels of attempted biting in the mirror treatment. Fourth, we examine the frequency and duration of surface breathing to gain insights regarding the effectiveness of mirrors compared to real opponents for eliciting agonistic displays. Because breathing rate has been linked to the vigour of displaying (Regan et al. 2015), we predict that should the display vigour differ between real and mirror opponents, there will be more surface breathing in the condition with higher vigour. However, there are two other aspects that might influence surface breathing. First, if the mirror offers a substandard stimulus resulting in a lower level of aggressive motivation then this might cause the fish to switch to breathing more frequently in the way that male newts breathe more readily when courting an unresponsive female (Halliday and Sweatman 1976). Note that the vigour of the displays might not necessarily differ with motivation because animals might not signal future intentions about persistence in contests (Dawkins and Krebs 1978). Another way that surface breathing might differ between real and mirror opponents is that fish might take their cues to breathe by the breathing 
145 attempts of the opponent. With a mirror the apparent opponent will not be the first to go to the

146 surface and will not be the first to resume displaying following surface breathing. This might

147 disrupt the pattern of breathing when compared to a real opponent. Using the information on

148 levels of surface breathing, coupled with information on contest behaviour, should enable us

149 to disentangle which of the above scenarios is correct.

150

\section{$151 \quad$ 2. Methods}

152

\subsection{Animals}

153 Thirty male, B. splendens were obtained from a local supplier (Grosvenor Tropicals, Belfast,

154 U.K.) in batches of six size-matched subjects and housed in individual glass tanks measuring $15530 \times 20 \mathrm{~cm}$ and $20 \mathrm{~cm}$ high, with approximately $2 \mathrm{~cm}$ depth of gravel. A controlled artificial $156 \quad 12: 12 \mathrm{~h}$ light:dark cycle was in place, tanks filled with 8 litres of treated tap water, aerated for 15730 minutes per day, and maintained at a temperature of $21-23^{\circ} \mathrm{C}$. Fish were fed daily with 158 flake food, and on the day of experimental trials were fed after observations had concluded.

\subsection{Experimental protocol}

161 Tanks were aligned end to end with opaque partitions visually isolating the fish outside of test sessions (as per Elwood et al. 2014). For at least 7 days prior to the onset of experimental trials the fish were maintained in these individual tanks, thus ameliorating any behavioural

164 effects of prior winning or losing experiences (reviewed in Hsu et al. 2006). Each fish was 165 tested twice, once displaying against a mirror and once against a real opponent, in a random 166 order and with a gap of 10-15 min between tests. When observations against the mirror were conducted the opaque partition between the two tanks was removed and immediately replaced with a 20 x $20 \mathrm{~cm}$ mirror and the focal fish was filmed for 15 minutes. When a real opponent 
was used the opaque partition was removed from between the two tanks and the focal fish was filmed for 15 minutes. During filming, the laboratory was isolated from disturbance. Each focal fish was exposed to the stimulus fish in the tank to the right, except for the last in the row of tanks, which was moved so that it could see the first fish as the stimulus $24 \mathrm{~h}$ after moving. Thus all focal fish/stimulus fish combinations were novel and pseudoreplication was avoided.

\subsection{Behavioural Measures}

Of the 30 tested male subjects, 10 were omitted from further analyses due to a lack of display behaviour by the focal or stimulus fish in one or both situations. Results are therefore based on recordings from 20 focal fish. The films were observed and behavioural displays recorded using Observer v. 3.0 software (Noldus Technology, Wageningen, The Netherlands). The following activities were recorded; left lateral display, right lateral display, frontal display, bite attempt and surface breathing. A left lateral display was recorded if the fish was displaying its left lateral side at 45 degrees or less to the glass at the end of the tank closest to the mirror/opponent, while a right lateral display if the right side was shown at 45 degrees or less, and a frontal display was recorded if the fish was head on to the glass ( $>45$ degrees) (as per Elwood et al. 2014). An attempted bite was recorded when a subject made open-mouthed contact with the glass/mirror, directed towards the real or perceived opponent. Surface breathing was recorded when a subject ceased displaying and began gulping air at the surface.

\subsection{Ethical note}

This study was carried out in accordance with the guidelines for the treatment of animals in behavioural research (ASAB 2012). Moreover, our experimental set-up prevented physical 
193

contact between fish, eliminating the risk of injury as a result of aggression, and staged

194 interactions were brief (as recommended by Huntingford 1984). Following discussions with

195 the local Home Office veterinary inspector it was deemed that there was no likelihood of fish

196 being harmed by the procedure and thus no licence was required. Further, the maintenance of

197 fish in individual tanks without transferring for each test ensured there was minimal handling,

198 disturbance, or opportunity to succumb to harm from conspecifics. Following the

199 experimental phase fish were returned unharmed to the local supplier.

200

201

202

203

204

205

206

207

\subsection{Statistical Analyses}

From behavioural observations, we obtained the frequency, total duration and median duration of each of the following activities; left lateral display, right lateral display, frontal display, surface breathing. In addition, we obtained the frequency of attempted bites. The data were not normally distributed and the nonparametric Wilcoxon matched-pairs signed ranks test for non-independent data was used to compare responses to real opponents and mirror images.

The same test was used to compare the frequency, total duration, and median durations of left and right lateral displays. Spearman rank correlations were used to examine relations between displays to mirrors and real opponents for each display component, as well as relations between surface breathing and agonistic activities. Although we used multiple tests, Bonferroni corrections were not applied given they have been criticised (Nakagawa 2004) for exacerbating the problem of low statistical power for behavioural studies, where the risk of Type II errors is generally greater than the risk of Type I errors. Moreover, we were interested in comparing overall patterns of behaviour between the two scenarios, therefore necessitating the need for multiple comparisons. Finally, any significant results we reported are also biologically plausible in light of previous findings (e.g. Elwood et al. 2014). All analyses were 
carried out using StatView (SAS Institute Inc., Cary, NC, U.S.A.).

\section{Results}

\subsection{Lateralization when displaying to a mirror and real opponent.}

221 With a real opponent there was a greater total duration of left side display compared to the 222 right side and a greater median duration of individual left lateral displays but not for the 223 frequency (Table 1). By contrast there was no lateral bias when displaying to a mirror (Table $1)$.

\subsection{Comparison of displays and surface breathing to a mirror and real opponent.}

There were no differences between a mirror image and live opponent in the frequencies, median durations and total durations of aggressive displays or frequency of biting (Table 2). However, surface breathing was greater to a mirror in terms of frequency, median duration and total duration (Figure 1, Table 2).

\subsection{Correlations between surface breathing and agonistic activities.}

233 When facing a real opponent the frequency of surface breaths was positively related to 234 various indicators of display vigour, in terms of the frequency of bite attempts, left lateral 235 displays, right lateral displays and frontal displays (Table 3). Further, the frequency of breaths 236 was negatively related to both the median duration of left lateral displays and the median 237 duration of frontal displays but did not relate to the total duration of left and right lateral 238 displays or frontal displays (Table 3). When facing a mirror the frequency of breathing events was positively related only to the frequency of biting events and negatively with the median duration of frontal displays but 
not to any other measure (Table 3).

3.4. Correlations for display components between mirror images and real opponents

244 The frequency of bites were positively correlated between the two conditions (Table 4). There

245 was a non-significant tendency for positive correlations between conditions for the frequency

246 of left lateral displays and right lateral displays but not for frontal displays. There were

247 positive correlations between the two conditions for the total duration of left lateral display

248 and for the right lateral display with the median durations of these displays also being

249 positively correlated between conditions. Other measures were not significantly related (Table $2504)$.

\section{Discussion}

253 We found evidence of population-level lateralization for lateral displays when facing a real 254 opponent, with a bias to present the left side and use the left eye, in terms of total duration and 255 the median duration of the individual aggressive displays but not for frequency. Preferential 256 use of the left side or left eye during aggressive encounters has been reported for many 257 vertebrates (Vallortigara and Rogers 2005). However, variable results have been reported for 258 different fish species, with some reporting a left side / eye use bias (Sovrano et al. 1999; 259 Ariyomo and Watt 2013) and others reporting a right side bias (Bisazza and de Santi 2003; 260 Arnott et al. 2011; Elwood et al. 2014). Further, the Siamese fighting fish of the present study 261 only showed a significant population bias when facing real opponents and not with a mirror 262 image. Similarly, Ariyomo and Watt (2013) reported greater left-eye preference in male 263 zebrafish when viewing a real opponent compared to a mirror image. However, previous 264 findings in Siamese fighting fish are conflicting, with Bisazza and de Santi (2003) finding a 
population-level bias with a mirror, whereas Cantalupo et al. (1996) and Takeuchi et al.

266 (2010) did not. Moreover, Elwood et al. (2014) found evidence of population-level

267 lateralization of convict cichlids in both the mirror and real opponent scenarios. This led to

268 the suggestion that the side-bias was a feature of the individual, rather than supporting a

269 previous suggestion (Arnott et al. 2011) that laterality provides a means for individuals to

270 coordinate their actions and cooperate in information exchange by aligning in a predictable

271 posture. The present findings add to recent and mounting evidence identifying influences of

272 lateralization on animal contest behaviour in a range of species (domestic cows, Phillips et al.

273 2015; fallow deer, Jennings 2012, 2014a, b; flies, Benelli et al. 2015a, b; Romano et al. 2015;

274 mosquitoes, Benelli et al. 2015c; Przewalski horses, Austin and Rogers 2014).

275 Previously, we reported distinct differences in the displays of convict cichlids to a

276 mirror compared to a real opponent (Elwood et al. 2014). In particular, the displays of cichlids

277 to a mirror appeared to be slower, with lower frequencies and longer individual displays to the

278 mirror image, explained by the apparent opponent in the mirror never making the first move

279 and thus failing to cause the focal fish to switch display (Elwood et al. 2014). In the present

280 study, however, we found no difference between aggressive displays to mirrors and to real

281 opponents. Further, we had speculated that Siamese fighting fish might respond to a mirror

282 image by escalating to biting more frequently or for longer because the image would not

283 cooperate as might a real opponent, but that was not the case. Thus, Siamese fighting fish

284 appear to display to mirror images in a similar manner to that of real opponents despite the

285 mirror image never making the first move or lining up in a head to tail configuration. It seems

286 that the displays of these fish are organised more in line with the endogenous motivation of

287 the focal fish rather than with the specific actions of the "opponent". This idea of the

288 endogenous motivation being a major factor in controlling the display actions is supported by 
our finding of positive correlations between aggressive activities to mirror and real opponents.

290 Such correlations have also been noted by others (Dore et al. 1978; Balzarini et al. 2014;

291 Elwood et al. 2014). Cichlids also fight mirrors and live rivals according to their own

292 endogenous motivation under normal conditions, but switch tactics to fight according to

293 opponent size when injected with isotocin (Reddon et al. 2012).

294 Despite the lack of differences in aggressive displays between the mirror and real 295 opponent conditions, there were distinct differences in surface breathing. Fish observing a 296 mirror image went to the surface substantially more often and each breathing event was of 297 longer duration resulting in a greater total duration spent surface breathing compared to when 298 confronting a real opponent.

Surface breathing is a means of getting additional oxygen that cannot be supplied in

300 the normal manner from the water via the gills. The number of breaths taken has been shown 301 here to be related to the vigour of displays in terms of positive relations with frequency, 302 particularly the biting frequency (see also Alton et al. 2013; Regan et al. 2015), and negatively 303 with the median duration, so we agree that breathing is typically affected, at least in part, by 304 oxygen requirement. However, we found no difference in the frequency or vigour of displays 305 between the mirror and real opponents and thus display vigour cannot account for the marked 306 difference in surface breathing frequency between these situations. The duration of each 307 surface breathing event was also greater to a mirror than to a real opponent. However, when 308 we examined correlations between median duration of breathing and other behavioural 309 measures no significant relations were found. Note that a longer time at the surface might not 310 necessarily mean that more oxygen is taken up at each visit. One possibility allowing for 311 differences in metabolic demand is that mirrors might induce a higher degree of fear 312 (Desjardins and Ferdinand 2010) and that fear might increase metabolic demand. However, 
this hypothesis requires experimental investigation.

314 If the increased breathing when confronted by a mirror is not due to a higher oxygen 315 requirement, it might be due to a lower motivation to display to the mirror. That is the mirror 316 image might provide an inappropriate, lower value stimulus for agonistic behaviour, which

317 then allows for the behaviour to be interrupted more frequently and for longer by a

318 subordinate activity (sensu McFarland and Sibly 1975; Halliday and Sweatman 1976).

319 Moreover, other researchers have previously suggested that air breathing can take the form of 320 a 'displacement' activity (Dore et al. 1978). Fight motivation might be reduced in the mirror 321 treatment but not result in reduced contest vigour compared to when facing a real opponent 322 because animals should not disclose future intentions in contests (Dawkins and Krebs 1978).

323 One way to clearly establish if this is the case would be to probe fight motivation using a 324 novel startling stimulus during the interaction. This causes an animal to temporarily break off 325 from the fight, with the time taken to resume the contest providing a measure of fight 326 motivation, with the technique having now been successfully used for a number of species 327 (e.g. hermit crabs; Elwood et al. 1998; fish, Arnott et al. 2009b, c, 2010; cuttlefish, Schnell et 328 al. 2015). Another explanation for the increased frequency and duration of surface breathing events in the mirror treatment is that breathing of the opponents under normal circumstances 331 is typically coordinated, with the fish engaging in near simultaneous air breathing (Simpson 332 1968). The mirror image cannot be the first to restart display, as might happen with a real 333 opponent causing the focal fish to respond. This might account for the increased duration of 334 surface breathing bouts in the mirror treatment. However, it is more difficult to use a similar 335 argument for the increased frequency of breathing. The mirror image cannot be the first to 336 initiate breathing and thus fewer breathing events should occur, the opposite to our findings. 
337 Conversely, in real contests should a focal animal show intention of going to the surface this

338 might be inhibited because the opponent continues to display. A mirror image will not

339 continue to display and thus might enable more frequent breathing.

340 The idea that the focal animal should attempt to match the display behaviour of the

341 opponent is predicted by some contest theory models (e.g. 'war of attrition without

342 assessment, Mesterton-Gibbons et al. 1996; 'energetic war of attrition', Payne and Pagel

343 1996, 1997) such that surface breathing is constrained to times of absolute need by both

344 opponents. Indeed, it is possible that with real opponents each attempts to prevent the other

345 from taking sufficient breaths and thus inflicts costs in terms of anaerobic respiration and

346 build-up of lactate. However, anaerobic capacity appears not to affect display vigour whereas

347 enhanced capacity for aerobic metabolism is linked to vigour and outcome (Regan et al.

348 2015). The idea of opponents influencing each other's surface breathing is further supported

349 by breathing being better correlated with fight behaviour when facing the real opponent

350 compared to the mirror treatment.

352 5. Conclusions

353 The lateralization of displays showed a left side bias but only when facing a real opponent and 354 not with a mirror image. Despite this difference in lateralization, fish did not differ in their 355 levels of aggressive displays to mirror images and real opponents. They did, however, differ 356 in surface breathing, with far more and longer breathing acts when facing a mirror image.

357 This could not be due to increased oxygen requirement when facing a mirror and the 358 increased frequency may be explained by a lower motivation to display to a mirror. The 359 increased duration might be due to the mirror image never being the first to resume displaying 360 and thus the image does not induce the focal fish to stop breathing and return to aggressive 
display. This study adds to mounting evidence of differences in behaviour when fish face a

362 mirror image compared to real opponent beyond a transparent barrier, therefore questioning

363 the utility of using mirrors. We accept, however, that even a live fish beyond a barrier is not

364 the same as interactions between unrestrained opponents.

\section{Acknowledgements}

We are grateful to Gillian Riddell for technical assistance. We also thank the editor and two anonymous reviewers for their useful comments and suggestions.

\section{References}

Alton, L.A., Portugal, S.J., White, C.R., 2013. Balancing the competing requirements of airbreathing and display behaviour during male-male interactions in Siamese fighting fish Betta splendens. Comp Biochem Physiol A Mol Integr Physiol 164, 363-367.

374 Ariyomo, T.O., Watt, P.J., 2013. Aggression and sex differences in lateralization in the zebrafish. Anim Behav 86, 617-622.

Arnott, G., Elwood, R.W., 2009a. Assessment of fighting ability in animal contests. Anim Behav 77, 991-1004.

Arnott, G., Elwood, R.W., 2009b. Probing aggressive motivation in a cichlid fish. Biol Lett 5, $762-764$.

Arnott, G., Elwood, R.W., 2009c. Gender differences in aggressive behaviour in convict cichlids. Anim Behav 78, 1221-1227.

382 Arnott, G., Elwood, R.W., 2010. Startle durations reveal visual assessment abilities during contests between convict cichlids. Behav Process 84, 750-756.

384 Arnott, G., Ashton, C., Elwood, R.W., 2011. Lateralization of lateral displays in convict 
cichlids. Biol Lett 7, 683-685.

386 ASAB., 2012. Guidelines for the treatment of animals in behavioural research and teaching. Anim Behav 83, 301-309.

Austin, N.P., Rogers, L.J., 2014. Lateralization of agonistic and vigilance responses in Przewalski horses (Equus przewalskii). Appl Anim Behav Sci 151, 43-50.

Backwell, P.R.Y., Christy, J.H., Telford, S.R., Jennions, M.D., Passmore, N.I., 2000. Dishonest signalling in a fiddler crab. Proc R Soc Lond B 267, 719-724.

Balzarini, V., Taborsky, M., Wanner, S., Koch, F., Frommen, J.G., 2014. Mirror, mirror on the wall: the predictive value of mirror tests for measuring aggression in fish. Behav Ecol Sociobiol 68, 871-878.

Benelli, G., Romano, D., Messing, R.H., Canale, A., 2015. Population-level lateralized aggressive and courtship displays make better fighters not lovers: evidence from a fly.

Benelli, G., Romano, D., Messing, R.H., Canale, A., 2015. First report of behavioural lateralization in mosquitoes: right-biased kicking behaviour against males in females of the Asian tiger mosquito, Aedes albopictus. Parasitol Res 114, 1613-1617.

Benelli, G., Donati, E., Romano, D., Stefanini, C., Messing, R.H., Canale, A., 2015 Lateralisation of aggressive displays in a tephritid fly. Sci Nat 102, 1.

Bisazza, A., de Santi, A., 2003. Lateralization of aggression in fish. Behav Brain Res 141, 131-136.

Bisazza, A., Cantalupo, C., Capocchiano, M., Vallortigara, G., 2000. Population lateralisation and social behaviour: A study with 16 species of fish. Laterality 5, 269-284.

407 Camerlink, I., Turner, S.P., Farish, M., Arnott, G., 2015. Aggressiveness as a component of 
fighting ability in pigs (Sus scrofa) using a game theoretical framework. Anim Behav $108,183-191$.

Cantalupo, C., Bisazza, A., Vallortigara, G., 1996. Lateralization of displays during aggressive and courtship behaviour in the Siamese fighting fish (Betta splendens). Physiol Behav 60, 249-252.

Castro, N., Ros, A.F.H., Becker, K., Oliveira, R.F., 2006. Metabolic costs of aggressive behaviour in the Siamese fighting fish, Betta splendens. Aggressive Behav 32, 474480.

Clutton-Brock, T.H., Albon, S.D., 1979. Roaring of red deer and the evolution of honest advertisement. Behaviour 69, 145-170.

Dawkins, R., Krebs, J.R., 1978. Animal signals: information or manipulation. In: Behavioural Ecology: an Evolutionary Approach. 1st edn (Ed. by J. R. Krebs \& N. B.Davies), pp. 282-309. Oxford: Blackwell Scientific.

Desjardins, J.K., Fernald, R.D., 2010. What do fish make of mirror images? Biol Lett 6, 744747.

Dore, F., Lefebvre, L., Ducharme, R., 1978. Threat Display in Betta splendens: Effects of water condition and type of agonistic stimulation. Anim Behav 26, 738-745.

Earley, R.L., Hsu, Y.Y., Wolf, L.L., 2000. The use of standard aggression testing methods to predict combat behaviour and contest outcome in Rivulus marmoratus dyads (Teleostei : Cyprinodontidae). Ethology 106, 743-761.

Elwood, R.W., Pothanikat, R.M.E., Briffa, M., 2006. Honest and dishonest displays, motivational state and subsequent decisions in hermit crab shell fights. Anim Behav 72, 853-859.

Elwood, R.W., Wood, K.E., Gallagher, M.B., Dick, J.T.A., 1998. Probing motivational state 
during agonistic encounters in animals. Nature 393, 66-68.

433 Elwood, R.W., Arnott, G., 2013. Assessments in contests are frequently assumed to be complex when simple explanations will suffice. Anim Behav 86, E8-E12.

Elwood, R.W., Arnott, G., 2012. Understanding how animals fight with Lloyd Morgan's canon. Anim Behav 84, 1095-1102.

Elwood, R.W., Prenter, J., 2013. Aggression in spiders. In I. C. W. Hardy \& M. Briffa (Eds), Animal Contests. Cambridge, U.K.: Cambridge University Press.

Elwood, R.W., Stoilova, V., McDonnell, A., Earley, R.L., Arnott, G., 2014. Do mirrors reflect reality in agonistic encounters? A test of mutual cooperation in displays. Anim Behav 97, 63-67.

Enquist, M., Leimar, O., 1983. Evolution of fighting behavior: Decision rules and assessment of relative strength. J Theor Biol 102, 387-410.

Enquist, M., Leimar, O., Ljungberg, T., Mallner, Y., Segerdahl, N., 1990. A test of the sequential assessment game: Fighting in the cichlid fish Nannacara anomala. Anim Behav 40, 1-14.

Fawcett, T.W., Mowles, S.L., 2013. Assessments of fighting ability need not be cognitively complex. Anim Behav 86, E1-E7.

Forsatkar, M.N., Dadda, M., Nematollahi, M.A., 2015. Lateralization of aggression during reproduction in male Siamese fighting fish. Ethology 121, 1039-1047.

Ghirlanda, S., Frasnelli, E., Vallortigara, G. 2009. Intraspecific competition and coordination in the evolution of lateralization. Philos T Roy Soc B 364, 861-866.

Halliday, T.R., Sweatman, H.P.A., 1976. To breathe or not to breathe: Newts problem. Anim Behav 24, 551-561. 
Press.

457 Hsu, Y.Y., Earley, R.L., Wolf, L.L., 2006. Modulation of aggressive behaviour by fighting experience: mechanisms and contest outcomes. Biol Rev 81, 33-74.

Huntingford, F.A. 1984. Some ethical issues raised by studies of predation and aggression. Anim Behav 32, 210-215.

Hurd, P.L., 1997. Cooperative signalling between opponents in fish fights. Anim Behav $54,1309-1315$.

Jennings, D.J., 2014. Limited evidence that visual lateralization is associated with fitness in rutting male fallow deer. Anim Behav 92, 85-91.

Jennings, D.J., 2014. Information gathering during contests: The relationship between lateralisation and contestant behaviour during fallow deer fights. Behav Process 103, 278-282.

Jennings, D.J. 2012. Right-sided bias in fallow deer terminating parallel walks: evidence for lateralization during a lateral display. Anim Behav 83, 1427-1432.

Jennings, D.J., Elwood, R.W., Carlin, C.M., Hayden, T.J. Gammell, M.P., 2012. Vocal rate as an assessment process during fallow deer contests. Behav Process 91, 152-158.

Jennings, D.J., Gammell, M.P., 2013. Ungulate contest behavior. In I. C. W. Hardy \& M. Briffa (Eds), Animal Contests (pp.304-320). Cambridge, U.K.: Cambridge University Press.

Mcfarland, D.J., Sibly, R.M., 1975. Behavioral final common path. Philos T Roy Soc B 270, 265-293.

Mesterton-Gibbons, M., Marden, J.H., Dugatkin, L.A., 1996. On wars of attrition without assessment. J Theor Biol 181, 65-83.

Nakagawa, S., 2004. A farewell to Bonferroni: the problems of low statistical power and 
publication bias. Behav Ecol 15, 1044-1045.

481 Oliveira, R.F., Carneiro, L.A., Canario, A.V.M., 2005. No hormonal response in tied fights. Nature 437, 207-208.

483

484

485

486

487

488

489

490

491

492

493

494

495

496

497

498

499

500

501

502

503

Ord, T.J., Evans, C.S., 2002. Interactive video playback and opponent assessment in lizards. Behav Process 59, 55-65.

Parker, G.A., 1974. Assessment strategy and evolution of fighting behavior. J Theor Biol $47,223-243$.

Payne, R.J.H., Pagel, M., 1997. Why do animals repeat displays? Anim Behav 54, 109-119.

Payne, R.J.H., Pagel, M., 1996. Escalation and time costs in displays of endurance. J Theor Biol 183, 185-193.

Phillips, C.J.C., Oevermans, H., Syrett, K.L., Jespersen, A.Y., Pearce, G.P., 2015.

Lateralization of behavior in dairy cows in response to conspecifics and novel persons. J Dairy Sci 98, 2389-2400.

Reddon, A.R., Balshine, S., 2010. Lateralization in response to social stimuli in a cooperatively breeding cichlid fish. Behav Process 85, 68-71.

Reddon, A.R., O’Connor, C.M., Marsh-Rollo, S.E., Balshine, S., 2012. Effects of isotocin on social responses in a cooperatively breeding fish. Anim Behav 84, 753-760.

Regan, M.D., Dhillon, R.S., Toews, D.P.L., Speers-Roesch, B., Sackville, M.A., Pinto, S., Bystriansky, J.S., Scott, G.R., 2015. Biochemical correlates of aggressive behavior in the Siamese fighting fish. J Zool 297, 99-107.

Reichert, M.S., Gerhardt, H.C., 2014. Behavioral strategies and signaling in interspecific aggressive interactions in gray tree frogs. Behav Ecol 25, 520-530.

Rogers, L.J., 1989. Laterality in animals. Int J Comp Psychol 3:5-25

Romano, D., Canale, A., Benelli, G., 2015. Do right-biased boxers do it better? Population- 
level asymmetry of aggressive displays enhances fighting success in blowflies. Behav Process 113, 159-162.

Schnell, A.K., Smith, C.L., Hanlon, R.T., Harcourt, R., 2015. Giant Australian cuttlefish use mutual assessment to resolve male-male contests. Anim Behav 107, 31-40.

Simpson, M.J., 1968. The threat display of the Siamese fighting fish, Betta splendens. Anim Behav Monogr 1, 1-73.

Sovrano, V.A., Rainoldi, C., Bisazza, A., Vallortigara, G., 1999. Roots of brain specializations: preferential left-eye use during mirror-image inspection in six species of teleost fish. Behav Brain Res 106, 175-180.

Takeuchi, Y., Hori, M., Myint, O., Kohda, M., 2010. Lateral bias of agonistic responses to mirror images and morphological asymmetry in the Siamese fighting fish (Betta splendens). Behav Brain Res 208, 106-111.

Taylor, P.W., Elwood, R.W. 2003. The mismeasure of animal contests. Anim Behav 65, 1195-1202.

Vallortigara, G., Rogers, L.J., 2005. Survival with an asymmetrical brain: Advantages and disadvantages of cerebral lateralization. Behav Brain Sci 28, 575-633.

Vallortigara, G., Rogers, L.J., Bisazza, A., 1999. Possible evolutionary origins of cognitive brain lateralization. Brain Res Rev 30, 164-175.

Van Dyk, D.A., Evans, C.S., 2008. Opponent assessment in lizards: examining the effect of aggressive and submissive signals. Behav Ecol 19, 895-901.

Wilson, A.J., de Boer, M., Arnott, G., Grimmer, A., 2011. Integrating Personality Research and Animal Contest Theory: Aggressiveness in the Green Swordtail Xiphophorus helleri. PloS One 6, e28024. 


\section{$528 \quad$ Figure captions}

529 Figure 1. Comparison of the frequency (a), total duration (b) and median duration (c) of

530 surface breathing when the focal fish $(n=20)$ displayed to a real opponent or mirror image. 
531 Table 1. Summary of results from Wilcoxon matched-pairs signed ranks tests, examining

532 lateralization of lateral displays to a mirror image and real opponent ( $\mathrm{n}=20$ focal fish). Median

533 values presented, and durations presented in seconds. Significant $\mathrm{P}$ values $(\mathrm{P}<0.05)$ are in

534 bold.

\begin{tabular}{lllll}
\hline Display measure & Left side & Right side & $Z$ statistic & $P$ value \\
\cline { 1 - 1 } Real opponent & 198.55 & 184.35 & -2.43 & $\mathbf{0 . 0 1 5}$ \\
\hline Total duration & 3.69 & 3.01 & -2.60 & $\mathbf{0 . 0 1 0}$ \\
\hline Median duration & 62.50 & 61.50 & -0.02 & 0.983 \\
\hline Frequency & 235.10 & 220.35 & 1.57 & 0.117 \\
\hline Mirror image & 3.31 & 3.19 & -0.49 & 0.627 \\
\hline Medal duration & & & & 0.144 \\
\hline Frequency & 67.50 & 60.00 & -1.46 & \\
\hline
\end{tabular}

535

536 
537 Table 2. Summary of results from Wilcoxon matched-pairs signed ranks tests, comparing

538 aggressive displays and surface breathing to a mirror and real opponent ( $\mathrm{n}=20$ focal fish).

539 Median values presented, and durations presented in seconds. Significant $\mathrm{P}$ values $(\mathrm{P}<0.05)$

540 are in bold.

541

\begin{tabular}{|c|c|c|c|c|}
\hline Display measure & Mirror image & Real opponent & $Z$ statistic & $P$ value \\
\hline Frequency & & & & \\
\hline Left lateral & 67.50 & 62.50 & -1.35 & 0.179 \\
\hline Right lateral & 60.00 & 61.50 & -0.50 & 0.614 \\
\hline Frontal & 91.50 & 88.00 & -0.49 & 0.624 \\
\hline Bites & 0.00 & 2.50 & -1.07 & 0.286 \\
\hline Surface breaths & 18.00 & 10.50 & -3.14 & 0.002 \\
\hline Total duration & & & & \\
\hline Left lateral & 235.10 & 198.55 & -0.67 & 0.502 \\
\hline Right lateral & 220.35 & 184.35 & -0.78 & 0.433 \\
\hline Frontal & 259.25 & 395.75 & -1.31 & 0.191 \\
\hline Surface breaths & 38.20 & 24.95 & -2.95 & 0.003 \\
\hline \multicolumn{5}{|l|}{ Median duration } \\
\hline Left lateral & 3.31 & 3.69 & -0.86 & 0.391 \\
\hline Right lateral & 3.19 & 3.01 & -0.85 & 0.398 \\
\hline Frontal & 2.43 & 3.77 & -0.97 & 0.332 \\
\hline Surface breaths & 2.29 & 2.07 & -2.093 & 0.036 \\
\hline
\end{tabular}

542 
546 Table 3. Spearman Rank correlations are shown for the frequency of surface breaths and

547 display components to a real opponent and a mirror image ( $\mathrm{n}=20$ focal fish). Correlations for 548 the median duration of breathing events and other display components are also shown for the

549 two conditions. Significant $\mathrm{P}$ values $(\mathrm{P}<0.05)$ are in bold.

550

\begin{tabular}{|c|c|c|c|c|c|c|c|c|}
\hline \multirow[t]{3}{*}{ Display measure } & \multicolumn{4}{|c|}{ Frequency of surface breaths } & \multicolumn{4}{|c|}{$\begin{array}{l}\text { Median duration of surface } \\
\text { breaths }\end{array}$} \\
\hline & \multicolumn{2}{|c|}{ Real opponent } & \multicolumn{2}{|c|}{ Mirror image } & \multicolumn{2}{|c|}{ Real opponent } & \multicolumn{2}{|c|}{ Mirror image } \\
\hline & $r_{s}$ & $P$ & $r_{s}$ & $P$ & $r_{s}$ & $P$ & $r_{s}$ & $P$ \\
\hline \multicolumn{9}{|l|}{ Frequency } \\
\hline Bites & 0.556 & 0.018 & 0.577 & 0.018 & -0.085 & 0.71 & 0.09 & 0.70 \\
\hline Left lateral & 0.706 & 0.002 & 0.297 & 0.198 & -0.17 & 0.45 & -0.13 & 0.56 \\
\hline Right lateral & 0.874 & 0.003 & 0.274 & 0.236 & -0.13 & 0.56 & -0.21 & 0.36 \\
\hline Frontal & 0.648 & 0.005 & 0.178 & 0.444 & 0.11 & 0.64 & -0.23 & 0.31 \\
\hline \multicolumn{9}{|l|}{ Total duration } \\
\hline Left lateral & 0.137 & 0.56 & 0.058 & 0.81 & 0.17 & 0.45 & -0.09 & 0.70 \\
\hline Right lateral & 0.279 & 0.229 & 0.37 & 0.109 & 0.314 & 0.17 & 0.05 & 0.82 \\
\hline Frontal & 0.143 & 0.54 & 0.072 & 0.76 & -0.12 & 0.60 & -0.35 & 0.12 \\
\hline \multicolumn{9}{|l|}{ Median duration } \\
\hline Left lateral & -0.531 & 0.019 & -0.130 & 0.56 & 0.33 & 0.15 & 0.07 & 0.75 \\
\hline Right lateral & -0.247 & 0.273 & 0.021 & 0.94 & 0.44 & 0.54 & 0.32 & 0.17 \\
\hline Frontal & -0.502 & 0.027 & -0.493 & 0.03 & 0.23 & 0.32 & -0.11 & 0.91 \\
\hline
\end{tabular}


553 Table 4. Correlations between specific display components to a mirror and those to real

554 opponents ( $\mathrm{n}=20$ focal fish). Significant $\mathrm{P}$ values $(\mathrm{P}<0.05)$ are in bold.

\begin{tabular}{lll}
\hline Display measure & Spearman $r_{s}$ & $P$ value \\
\cline { 1 - 1 } Frequency & 0.676 & $\mathbf{0 . 0 0 3}$ \\
\hline Bites & 0.445 & 0.052 \\
\hline Reft lateral & 0.409 & 0.075 \\
\hline Frontal & 0.243 & 0.290 \\
\hline Surface breaths & 0.379 & 0.10 \\
\hline Total duration & 0.507 & $\mathbf{0 . 0 2 7}$ \\
\hline Left lateral & 0.531 & $\mathbf{0 . 0 2 1}$ \\
\hline Right lateral & 0.397 & 0.084 \\
\hline Frontal & 0.322 & 0.160 \\
\hline Surface breaths & 0.605 & $\mathbf{0 . 0 0 8}$ \\
\hline Median duration & 0.770 & $\mathbf{0 . 0 0 1}$ \\
\hline Left lateral & -0.053 & 0.820 \\
\hline Right lateral & 0.459 \\
\hline Frontal & & \\
\hline Surface breaths & & \\
\hline & & \\
\hline & & \\
\hline
\end{tabular}


Figure 1.
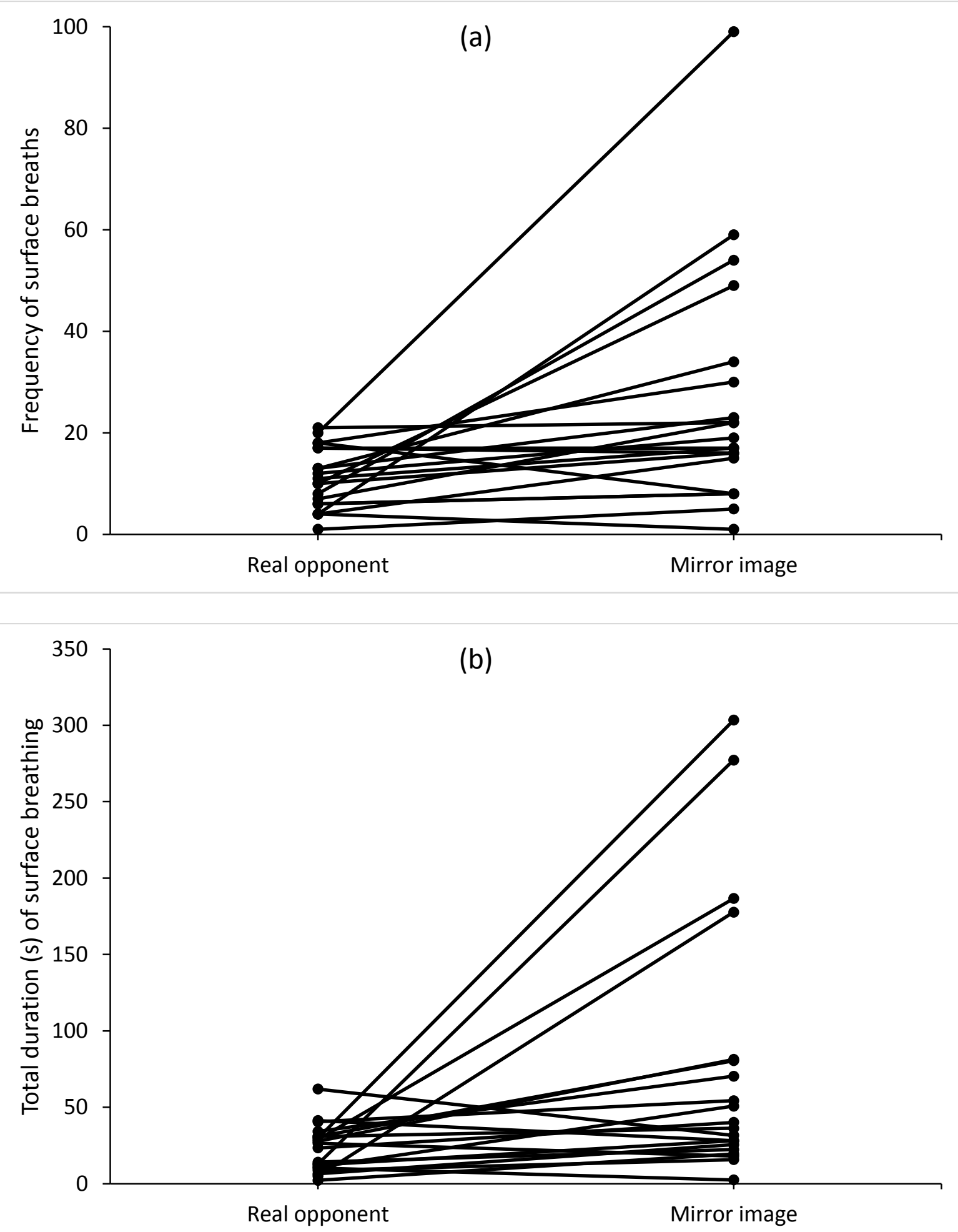


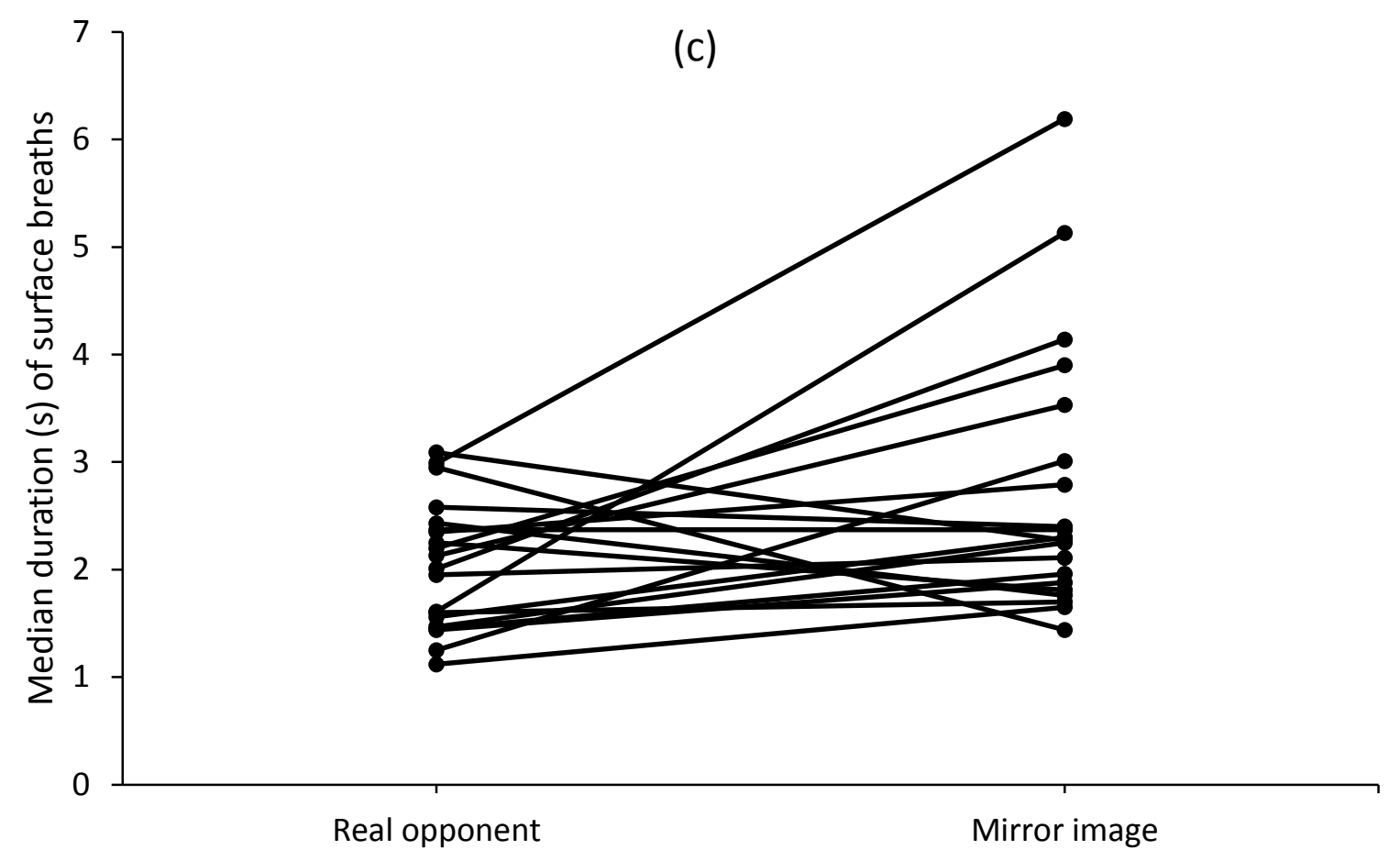

